\title{
O CONCEITO DE TRABALHO E O TRABALHO DO CONCEITO NA FILOSOFIA DE HEGEL: APONTAMENTOS INTRODUTÓRIOS
}

\author{
The Concept of Work and the Work of Concept in the Philosophy of Hegel: introductory notes
}

Messias Silva Manarim*

Resumo: O trabalho é um tema muito presente na filosofia hegeliana. O mesmo é discutido em diversos dos seus textos. Centralmente aparece nas figuras do senhor e do escravo, na Fenomenologia do Espírito, em que ele retrata a luta pelo reconhecimento de uma consciência frente à outra, além de apontar que o processo de dominação do senhor está relacionado à necessidade que o mesmo tem de satisfazer os seus desejos, mas para isso se utiliza do trabalho do escravo. Ocorre que o trabalho do escravo ao realizar o desejo do senhor, acaba por dar forma ao que antes era somente ideia, desejo. Esse processo leva o escravo a um princípio de sabedoria, principia a liberdade. $\mathrm{O}$ trabalho permite também a interação social entre as pessoas, pois todos participam da sua produção e do gozo dos seus resultados. Ainda para Hegel, o trabalho permitirá à superação do trabalho humano pelo trabalho mecânico. E, por fim, destaca-se haver a característica fundamental de existir o trabalho do espírito, que é a ação de persecução do conceito, ou seja, o trabalho da consciência para se atingir cada conceito.

Palavras-chave: Trabalho, Dialética, Hegel.

\begin{abstract}
Labor is a widely present subject in hegelian philosophy, discussed in many of his texts. It centrally appears in the pictures of the master and the slave, in his Phenomenology of Spirit, in which he illustrates the struggle for the recognition of one self-consciousness by another; he remarks that the process of domination by the master is related to one's need to fulfull one's own desires, but for that, the labor of the slave is employed. It so happens that the labor of the slave, when carrying out the desires of the master, ends up materializing what before was only an idea, a will. This whole process brings the slave to a beginning of wisdom, giving way to freedom. Labor also enables the interaction between people, since everyone participates in this production and the enjoyment of its results. In addition, for Hegel, labor will enable the surpassing of the human workforce by the machine workforce. In the end, the fundamental need to occur a labor of the spirit is highlighted, wich is the action of pursuing the concept - that is, the work of the mind in order to reach every concept.
\end{abstract}

Keywords: Labor, Dialetics, Hegel.

* Mestrando do Programa de Pós-Graduação em Filosofia da UFSC. E-mail: msmanarim@gmail.com. Telefone: (48) 9991-5660.

\begin{tabular}{|c|c|l|l|l|l|}
\hline intuitio & $\begin{array}{c}\text { ISSN } \\
1983-4012\end{array}$ & Porto Alegre & Vol.10 $-\mathrm{N}^{\mathrm{o}} .1$ & $\begin{array}{l}\text { Julho } \\
2017\end{array}$ & p. 123-134 \\
\hline
\end{tabular}




\section{Introdução}

A filosofia de Hegel está inserida num contexto de transformação radical de como os seres humanos estavam produzindo as coisas necessárias à satisfação das suas necessidades, ou seja, vivíamos o momento de transição das sociedades chamadas pré-capitalistas (no caso europeu, da sociedade feudal) para a moderna sociedade capitalista. Atingir esse novo modo de viver não foi de simples mudanças no cotidiano, mas de mudanças radicais na forma de como as pessoas viviam, pensavam, produziam.

O século XVIII é conhecido pela Ilustração, o momento em que a razão substitui a escuridão do mundo anterior, preso às divindades. Também é o século em que se concretizam a Revolução Francesa e a Independência dos Estados Unidos da América, momentos cruciais para uma nova ordem burguesa que estava se estabelecendo. Essas são as revoluções que movem o campo do pensamento, da política e também uma revolução nas ciências está acontecendo. Mas, não se limita a esses campos, na esteira desse processo tem-se uma revolução na forma de como se produz a vida, está acontecendo a Revolução Industrial, em que o centro da vida não é mais a bucólica paisagem rural, mas a agitada urbe. Temos uma modificação brutal do lugar onde se vive, saindo de uma labuta diária com instrumentos rudimentares para um trabalho que agora passa a ser dividido entre muitas pessoas, onde não se domina por completo a produção de um objeto e o objetivo não é mais produção da subsistência, mas a produção das mercadorias, e a sobrevivência mediada por uma contraprestação salarial.

Esses elementos da sociedade emergente, a capitalista, Hegel não esconde seu interesse sobre eles no caminho que percorre filosoficamente. Nesse processo todo, o momento mais marcante para os comentadores da filosofia hegeliana vem a ser a dialética da dependência e da independência da consciência-de-si, que tem nas figuras do senhor e do escravo um processo de transição entre uma consciência das coisas, presa ao mundo da natureza, para uma consciência-de-si. Ou seja, uma consciência do eu, que coloca não somente uma indagação sobre o mundo natural, mas sobre si mesma, sendo um momento crucial para o reencontro do espírito consigo mesmo.

Desta forma, esse importante movimento terá no trabalho um de seus conceitos primordiais e que será decisivo na conformação filosófica hegeliana. Além desse movimento, buscaremos traçar elementos que apontem em outra direção, no caso, a do trabalho do conceito, mas deteremo-nos no conceito de trabalho nas análises que seguem.

\section{O conceito de Trabalho}

\subsection{A consciência-de-si e o despertar do trabalho}

\begin{tabular}{|c|c|l|l|l|l|}
\hline intuitio & $\begin{array}{c}\text { ISSN } \\
1983-4012\end{array}$ & Porto Alegre & Vol.10 $-\mathrm{N}^{\mathrm{o}} .1$ & $\begin{array}{l}\text { Julho } \\
2017\end{array}$ & p. 123-134 \\
\hline
\end{tabular}


A consciência-de-si é nesse processo o segundo momento geral dessa consciência do espírito, pois o primeiro momento é constituído de três movimentos internos: a certeza sensível, a percepção e o entendimento. Quando se chega ao entendimento, a consciência do espírito não se dá por reconstituída, mas permanece no seu caminho, aqui se sai de uma consciência mais ligada à experiência das coisas, como as percebemos, como entendemos o jogos de forças das leis da natureza para uma consciência que não somente estará vinculada a esse mundo do entendimento, mas que passa a ser uma consciência que vai questionar a si mesma, vai se reconhecer como um eu, mesmo que ainda não totalmente livre, pois isso só será alcançado no saber absoluto, depois de longa reconstituição. Mas o saber absoluto não se constitui num saber total e completo sobre as coisas, ou seja, não é o ponto final do desenvolvimento do sistema, pois Hegel ainda trabalhará a lógica e o espírito absoluto. Dessa forma, o saber absoluto, que é o saber de um saber, se constitui no começo da ciência.

Estamos atentos a esse momento, o da consciência-de-si, já que aqui está a primeira exposição em que o trabalho assume uma conotação decisiva na filosofia hegeliana, pois se constitui no elemento que fará o escravo sair da sua condição de uma consciência servil, que não é livre. Vejamos como esse movimento se constitui: o senhor é num primeiro momento independente frente ao escravo, pois já não está preso ao mundo da vida, o de produzir as coisas que deseja, enquanto que o escravo está limitado a essa relação de dominação, dependente dela, pois está preso a produzir as coisas que o senhor deseja. Mas, para se chegar nessa situação teve de ocorrer uma luta entre essas duas consciências, e uma teve de recuar, pois senão teria morrido. Ou seja, o senhor domina o escravo porque este desistiu da liberdade para se manter vivo, com isso preferiu trabalhar para o senhor.

Mas aí está também presente o segundo agir, o agir por meio de si mesmo, pois aquele agir do Outro inclui o arriscar a própria vida. Portanto, a relação das duas consciências-de-si é determinada de tal modo que elas se provam a si mesmas e uma a outra através de uma luta de vida ou morte ${ }^{1}$

Nesse momento ocorre o processo da luta das consciências, se experimentam, sabem que somente uma sairá viva dessa luta e, por isso, uma delas não se arrisca para ser livre, mas a outra o faz. Quem se arrisca, demonstra claramente a intenção de ser uma consciência livre, por isso ao findar a luta temos o senhor, essa consciência livre e o escravo que preferiu a vida do que lutar até à morte pela liberdade. Aqui é um momento em que temos claramente a relação de dominação de uma consciência sobre a outra. Mas, fica patente que uma consciência é reconhecida pela outra, enquanto que a outra não tem esse

\footnotetext{
${ }^{1}$ HEGEL, G. W. F. Fenomenologia do espírito. Tradução de Paulo Meneses com a colaboração de Karl-Heinz Efken e José Nogueira Machado. $7^{\text {a }}$ ed. Petrópolis: Vozes; Bragança Paulista: Editora Universitária São Francisco, 2012. p. 145.
}

\begin{tabular}{|c|c|c|c|c|c|}
\hline intuitio & $\begin{array}{c}\text { ISSN } \\
1983-4012\end{array}$ & Porto Alegre & Vol.10 - No.1 & $\begin{array}{l}\text { Julho } \\
2017\end{array}$ & p. 123-134 \\
\hline
\end{tabular}


O Conceito de Trabalho e o Trabalho do Conceito na Filosofia de Hegel: apontamentos introdutórios

reconhecimento, ao contrário, reconhece-se na outra consciência e não em si mesmo. O senhor é uma consciência que é reconhecida como consciência senhora pela consciência escrava, o mesmo já não acontece com a consciência escrava, que não é reconhecida, é um ser subjugado, dominado. Mas nesse momento inclusive há um estranhamento do escravo, já que não se reconhece enquanto tal, pois ao se reconhecer, a consciência senhora acaba por estranhar-se a si mesma e se reconhece como consciência senhora.

Esse momento não se encerra aqui, pois como dizíamos antes a consciência senhora não trabalha, não produz as coisas que deseja, ou seja, quem as faz é o escravo. Então, a consciência do senhor é uma consciência que deseja, mas que não é capaz de realizar seu próprio desejo, e para isso se utiliza do escravo, que não deseja as coisas, mas as produz para o senhor. Aqui temos que o senhor é dependente da coisa da qual deseja e o escravo não. Temos de destacar que a relação entre o senhor e o escravo dá-se pela coisa, pois enquanto um é produtor, o outro é o consumidor. Isso faz com que a relação que ambos tenham é mediada pela coisa.

O senhor também se relaciona mediatamente por meio do escravo com a coisa; o escravo, enquanto consciência-de-si em geral, se relaciona também negativamente com a coisa, e a suprassume. Porém, ao mesmo tempo, a coisa é independente para ele, que não pode portanto, através do seu negar, acabar com ela até a aniquilação; ou seja, o escravo somente a trabalha. Ao contrário, para o senhor, através dessa mediação, a relação imediata vem-a-ser como a pura negação da coisa, ou como gozo - o qual the consegue o que o desejo não conseguia: acabar com a coisa, e aquietar-se no gozo. O desejo não o conseguia por causa da independência da coisa; mas o senhor introduziu o escravo entre ele e a coisa, e assim se conclui somente com a dependência da coisa, e puramente a goza; enquanto o lado da independência deixa-o ao escravo, que a trabalha. ${ }^{2}$

Temos que a relação entre ambos é mediada pela coisa. O escravo é quem trabalha a coisa, a transforma, ou seja, pela sua ação realiza o que era desejo do senhor. Consegue dar forma ao que antes era só a ideia, mas para realizar isso tem de fazer com a coisa bruta, que vem da natureza, passe a ser uma coisa passível de ser consumida, uma coisa trabalhada. Esse agir do escravo é destacado no seguinte comentário:

Para Hegel, o homem só é o que é pela ação; ele é a ação. Ele só é objeto real na medida em que se realizou pela ação no mundo. (A ação realizadora da humanidade é a transformação visível da natureza pelo trabalho). Não há homem que realize sua obra; ele é a obra que realizou. ${ }^{3}$

\footnotetext{
${ }^{2}$ HEGEL, G. W. F. Fenomenologia do espírito. Tradução de Paulo Meneses; com a colaboração de Karl-Heinz Efken e José Nogueira Machado. $7^{a}$ ed. Petrópolis: Vozes; Bragança Paulista: Editora Universitária São Francisco, 2012. p. 148.

${ }^{3}$ KOJÈVE, A. Introdução à leitura de Hegel. Tradução Estela dos Santos Abreu. Rio de Janeiro: Contraponto, 2014. p. 88.
}

\begin{tabular}{|c|c|l|l|l|l|}
\hline intuitio & $\begin{array}{c}\text { ISSN } \\
1983-4012\end{array}$ & Porto Alegre & Vol.10 $-\mathrm{N}^{\mathrm{o}} .1$ & $\begin{array}{l}\text { Julho } \\
2017\end{array}$ & p. 123-134 \\
\hline
\end{tabular}


A coisa é chamada de coisa independente nesse momento, pois o escravo que a produziu não tem qualquer controle sobre ela, já que ao ter trabalhado a coisa, transformou o que era natural num constructo humano. Nesse momento, em que a coisa foi finalizada, o escravo não tem qualquer controle sobre a existência da mesma, pois a própria autonomizou-se frente ao produtor. Já o senhor mantém a dependência sobre a coisa que deseja, pois depende dela para manter a sua existência. Assim, o senhor consegue efetivar o que antes era desejo, mas para alcançar isso teve de inserir entre ele e a coisa o próprio escravo, pois por si mesmo não conseguiria efetivar esse desejo, o mesmo se manteria presa na sua ideia.

Nesse momento temos de chamar à atenção para o que move o escravo à ação: ele é movido pelo temor que tem sobre a sua vida. Para entender esse momento temos de recorrer à ideia de que o senhor venceu a batalha que teve com o escravo, por isso o dominou e o colocou a trabalhar, dessa forma, temos que o escravo antes de ser escravizado fez a escolha por se manter vivo, ter uma vida natural, não a quis arriscar, como fez o senhor. Então o temor é algo que está presente no escravo desde o início do processo de dominação que ele poderia ter abdicado, ao ter escolhido a morte.

Temos que o escravo é impelido a agir pelo medo, medo de perder a vida, por isso que ele produz, e produz a realização dos desejos do senhor. Este temor lhe invade toda a sua existência, lhe impele a ação de transformar a coisa, de dar forma ao desejo do senhor, aqui temos o que Hegel chama de uma superação da situação anterior. Pois se antes o escravo estava dominado, subjugado, tinha a sua existência dependente do senhor, agora temos que o senhor é que depende da coisa produzida pelo escravo, a consciência escrava toma conhecimento de si como produtora, como a que pode dar forma às coisas que se deseja, ou seja, o engenho humano começa a agir sobre o mundo natural, transformando-o.

A forma não se torna um outro que a consciência pelo fato de se ter exteriorizado, pois justamente essa forma é seu puro ser-para-si, que nessa exteriorização vem-a-ser para ela verdade. Assim, precisamente no trabalho, onde parecia ser apenas um sentido alheio, a consciência, mediante esse reencontrar-se de si por si mesma, vem-a-ser sentido próprio ${ }^{4}$.

Apesar da dificuldade que o texto nos traz, extraímos daqui que o trabalho consegue objetivar aquilo que era somente ideia nesse processo, ou seja, tem a capacidade de dar a consciência o seu sentido próprio. Pois, se antes de trabalhar a coisa o que tínhamos era a ideia, o desejo, algo sem forma, agora passamos a ter a materialização do que antes era apenas um ensaio do espírito. Aqui ele chama atenção para uma característica importante, pois se no primeiro momento da relação entre o senhor e o escravo

${ }^{4}$ HEGEL, G. W. F. Fenomenologia do espírito. Tradução de Paulo Meneses; com a colaboração de Karl-Heinz Efken e José Nogueira Machado. $7^{a}$ ed. Petrópolis: Vozes; Bragança Paulista: Editora Universitária São Francisco, 2012. p. 151.

\begin{tabular}{|c|c|l|l|l|l|}
\hline intuitio & $\begin{array}{c}\text { ISSN } \\
1983-4012\end{array}$ & Porto Alegre & Vol.10 $-\mathrm{N}^{\mathrm{o}} .1$ & $\begin{array}{l}\text { Julho } \\
2017\end{array}$ & p. 123-134 \\
\hline
\end{tabular}


tínhamos que o trabalho parecia ser um sentido alheio à própria consciência, o que fica demonstrado é que o trabalho é o que propicia um reencontro da consciência por si mesma, pois o trabalho ao efetivar a ideia, ao dar forma à coisa, realiza essa consciência, que se reencontra consigo mesma.

[...] o escravo forma-se a si mesmo não somente ao formar as coisas, mas também imprime no ser essa forma que é a da consciência de si, e assim o que encontra em sua obra é ele mesmo. [...]O trabalho do escravo atinge a contemplação do ser independente como sendo de si mesmo. ${ }^{5}$

Dessa forma, a consciência passa a ser sentido próprio, uma consciência-de-si. É a partir desse substancial momento do agir da consciência escrava, que se principia na mesma a sabedoria, ou seja, a liberdade. Pois a consciência escrava consegue fazer o que a consciência senhora não consegue, dar forma a ideia, ao desejo, efetivar. Isso torna o escravo o senhor da natureza, como apontado:

Quando, pelo trabalho, se torna senhor da natureza, o escravo liberta-se de sua própria natureza, do instinto que o ligava à natureza e que fazia dele o escravo do senhor. Ao libertar o escravo da natureza, o trabalho também o liberta de si próprio, de sua natureza de escravo: liberta-o do senhor. No mundo natural, dado, bruto, o escravo é escravo do senhor. No mundo técnico, transformado por seu trabalho, o escravo reina - ou, pelo menos, reinará um dia - como senhor absoluto. ${ }^{6}$

Nesse momento, temos que a consciência escrava ao superar a condição de dominação que lhe estava imposta, ascende à liberdade. É uma consciência que consegue superar a condição de sua dependência frente à vida, pois a transforma, se alça em novos momentos, o que Hegel expõe como consciência infeliz (cristã), no estoicismo e no ceticismo, pois essa consciência que consegue se libertar da coisa, decepciona-se com o mundo.

\subsection{Da singularidade ao universal: a divisão do trabalho}

Temos de nos concentrar mais no trabalho, pois se nesse momento a consciência escrava consegue se libertar da coisa, pois a produz, a coisa ganha autonomia do produtor. Vamos a um novo passo, noutro momento Hegel destaca que não se limita a uma consciência singular, mas que se passa a uma consciência universal através da ação de produzir. Destaca um aspecto dessa modernidade nascente que elevou o trabalho a sua máxima divisão, como antes ressaltamos sobre a Revolução Industrial. Esse é o primeiro momento em que a cooperação entre os seres humanos chega a limites extremos, o que ficou conhecido

${ }^{5}$ HYPPOLITE, J. Gênese e estrutura da Fenomenologia do Espírito de Hegel. Tradução de Sílvio Rosa Filho. 2 ed. São Paulo: Discurso Editorial, 2003. p. 191.

${ }^{6}$ KOJÈVE, A. Introdução à leitura de Hegel. Tradução Estela dos Santos Abreu. Rio de Janeiro: Contraponto, 2014. p. 26.

\begin{tabular}{|c|c|c|c|c|c|}
\hline intuitio & $\begin{array}{c}\text { ISSN } \\
1983-4012\end{array}$ & Porto Alegre & Vol.10 $-\mathrm{N}^{\circ} .1$ & $\begin{array}{l}\text { Julho } \\
2017\end{array}$ & p. 123-134 \\
\hline
\end{tabular}


como divisão do trabalho. Nesse processo os indivíduos estão reunidos dentro das indústrias, e cada um realiza uma parte do trabalho correspondente à formação da coisa, ou seja, temos uma cooperação entre os indivíduos com a finalidade de produzir bens materiais, produzir objetos que sejam úteis à satisfação das necessidades das pessoas.

Neste momento Hegel destaca que não há uma produção de todas as coisas que as pessoas precisam por um único indivíduo, ou seja, não consegue satisfazer as suas necessidades somente com o seu trabalho e ao mesmo tempo o seu trabalho serve à satisfação das necessidades alheias. Assim, temos que o indivíduo ao trabalhar, produz a satisfação das suas necessidades e também das alheias, da mesma forma que o trabalho alheio o ajudará a satisfazer as suas necessidades. "O trabalho do indivíduo para [prover às] suas necessidades é tanto satisfação das necessidades alheias quanto das próprias; e o indivíduo só obtém a satisfação de suas necessidades mediante o trabalho dos outros"7. Aqui Hegel destaca como o trabalho tem uma dimensão social, não fica adstrito ao indivíduo. Tem-se que individualmente não se conseguirá efetivar todas as nossas necessidades dada a dinâmica da vida que temos, teremos de recorrer ao trabalho alheio, ou seja, o trabalho socialmente produzido. Temos que o indivíduo produz para um montante que será socialmente consumido, esse montante é chamado riqueza. Da riqueza todos contribuem com o seu trabalho, e dela retiram o que precisam para satisfazer as suas necessidades, participam do gozo dessa riqueza. Isso é claramente uma avaliação da moderna sociedade industrial, sociedade pautada por uma nova forma de trabalho.

Temos de explorar um pouco mais a ideia de necessidade, carências, que é justamente aquilo que moverá a ação humana para o trabalho. A necessidade é aquilo que está na gênese desse movimento, pois impele o homem a ir em busca dessa satisfação, uma vez que tem que se manter vivo, tem que manter esse corpo funcionando mesmo que o trabalho o liberte do mundo natural, pois como transforma a natureza acaba por não depender dela, assim consegue sua superação, já que pela razão tem a capacidade de agir sobre aquilo que deseja produzir.

A discussão do trabalho na obra hegeliana não se limita a Fenomenologia do Espírito, mas está presente em outros textos do autor, como a Filosofia do Direito e a Enciclopédia das Ciências Filosóficas em Compêndio. Na Filosofia do Direito ele reserva um item dentro da discussão dos carecimentos (necessidades) e a sua satisfação, assim apresenta novamente a relação que temos da satisfação das necessidades mediante o trabalho, como ele destaca no trecho a seguir:

\footnotetext{
7 HEGEL, G. W. F. Fenomenologia do espírito. Tradução de Paulo Meneses; com a colaboração de Karl-Heinz Efken, e José Nogueira Machado. $7^{\mathrm{a}}$ ed. Petrópolis: Vozes; Bragança Paulista: Editora Universitária São Francisco, 2012. p. 251.
}

\begin{tabular}{|c|c|c|c|c|r|}
\hline intuitio & $\begin{array}{c}\text { ISSN } \\
1983-4012\end{array}$ & Porto Alegre & Vol.10- No.1 & $\begin{array}{l}\text { Julho } \\
2017\end{array}$ & p. 123-134 \\
\hline
\end{tabular}


O Conceito de Trabalho e o Trabalho do Conceito na Filosofia de Hegel: apontamentos introdutórios

A mediação, a fim de preparar e adquirir para os carecimentos particularizados meios apropriados igualmente particularizados é o trabalho, o qual pelos mais diversos processos especifica o material imediatamente fornecido pela natureza para esses fins múltiplos. Essa elaboração dá então ao meio seu valor e sua conformidade ao fim, de modo que o homem em seu consumo se relaciona principalmente com produções humanas, e tais esforços são o que ele utiliza. ${ }^{8}$

Notamos nesta passagem que é o trabalho para Hegel o responsável por garantir a satisfação das necessidades particulares, ou seja, as necessidades particulares precisam de bens particulares, feitos especificamente para a satisfação das mesmas. Denotamos aqui que o trabalho tem a capacidade de atingir a singularidade a que estamos imersos, já que as singularidades se multiplicam sobre nosso olhar, não ficam limitadas a simples afirmações que fazemos, e muito menos às parcas ideias que imediatamente talvez tenhamos. Mas sim que o trabalho tem o requinte de possibilitar-nos a satisfação dos desejos mais particulares.

Aponta que o homem se relaciona com produções humanas, ou seja, que as pessoas se relacionam por aquilo que produzem na busca de satisfazer as suas necessidades. Além disso, isso nos dá entender que ao consumirmos aquilo que foi produzido pelos humanos, nos relacionamos de certa forma com os próprios seres humanos que transformaram os elementos da natureza, que permitiram constituir as condições sobre determinados objetos antes limitados ao nosso desejo. É o trabalho que, como já reiterado anteriormente, nos permite realizar as ideias que antes estavam limitadas ao desejo, ou seja, o trabalho é formador. Ele dá forma às coisas que precisamos para a satisfação das nossas necessidades, mais do que isso, ao produzirmos as coisas das quais as pessoas precisam para sobreviver mediante o trabalho, temos o trabalho como um elemento central nas relações humanas.

Essa conexão social promovida pelo trabalho é ressaltada a seguir:

O trabalho, que por isso é ao mesmo tempo mais abstrato, conduz de um lado, por sua uniformidade, à facilitação do trabalho e ao aumento da produção; de outro lado, à limitação a uma habilidade única, e assim à dependência mais incondicionada em relação à conexão social. A habilidade mesma torna-se, dessa maneira, mecânica e recebe a capacidade de deixar a máquina tomar o lugar do trabalho humano ${ }^{9}$

A divisão do trabalho aqui é demonstrada como um fator importante na perspectiva até que de certa forma emancipatória do homem frente ao trabalho. Analisa que o trabalho é abstrato, ou seja, não consegue ser determinado num indivíduo, pois é o resultado da ação de diversas pessoas. Mas tem

\footnotetext{
${ }^{8}$ HEGEL, G. W. F. Linhas fundamentais da filosofia do direito ou Direito natural e ciência do estado em compêndio. Tradução de Paulo Menezes, Agemir Bavaresco, Alfredo Moraes, Danilo Vaz-Curado R. M. Costa, Greice Ane Barbieri e Paulo Roberto Konzen. 2a ed. São Leopoldo: UNISINOS, 2010. p. 196.

${ }^{9}$ HEGEL, G. W. F. Enciclopédia das ciências filosóficas em compêndio: 1830. Texto completo com os adendos orais traduzido por Paulo Menezes e com a colaboração de José Machado. 2a ed. São Paulo: Loyola, 2011. p. 298.
}

\begin{tabular}{|c|c|c|c|c|c|}
\hline intuitio & $\begin{array}{c}\text { ISSN } \\
1983-4012\end{array}$ & Porto Alegre & Vol.10 - No.1 & $\begin{array}{l}\text { Julho } \\
2017\end{array}$ & p. 123-134 \\
\hline
\end{tabular}


características que poderíamos chamar de positivas, como a uniformidade, o aumento da produção e a facilitação, com isso fica claro aqui que a entrada da máquina é decisiva para esse processo. Pois, como teríamos essas características na ação laborativa sem a presença da máquina, já que teríamos somente trabalhadores produzindo espalhados, da forma que melhor entendem e ainda produzindo pouco, já que tem de realizar seu trabalho com artefatos rudimentares ou mesmo trabalhar solitariamente.

As características que demonstram certa negatividade são o fato do trabalhador ter suas habilidades reduzidas a determinado setor de produção de determinada coisa, e não mais dominar o processo por completo, como acontecia com os trabalhadores antes da Revolução Industrial, em que sabia fazer todas as partes de determinado produto. E, com isso se tem uma dependência do meio social, que não mais se poderá abdicar, ou seja, perde-se a possibilidade de individualmente dar conta de subsistir, torna-se mais dependente da sociedade, daquilo que socialmente foi produzido.

Chama-nos a atenção o fato de Hegel supor a substituição do trabalho humano pelo trabalho da máquina. Como que se por meio da especialização da habilidade se traçasse uma linha entre o momento anterior que não se tinha a divisão do trabalho, e agora devido a necessidade de especificação na atividade laborativa, chega-se a tal grau da mesma, que primeiro essa própria habilidade torna-se mecânica, e vai-se substituindo o fazer humano pelo mecânico até que a máquina suplante a ação humana. Essa ideia ele retoma em outra passagem: "A abstração do produzir torna o trabalho, além disso, sempre mais mecânico e, com isso, torna-o no fim apto para que o homem possa dele se retirar e deixar a máquina entrar em seu lugar"10.

Essa importante afirmação de Hegel nos permitirá debater como a máquina tem uma importância para todo esse processo de transformação das relações entre os seres humanos. Muito claramente ele destaca a superação do trabalho físico para o mecânico, o que permitiria mais tempo livre ao invés de estarmos presos à busca da satisfação das nossas necessidades, produzindo coisas, agindo pelo trabalho. Mas isso destaca um elemento crucial para este filósofo: a ideia que estamos caminhando para o progresso, ou seja, a sua filosofia é vinculada a uma ideia de que pelo conhecimento atingiríamos sempre mais elementos para a liberdade. É assim com a reconstituição do caminho do espírito, que a cada figura ao ir se reencontrando consigo chega no saber absoluto, onde ter-se-ia o saber de um saber, o início da ciência, como destacado anteriormente.

${ }^{10}$ HEGEL, G. W. F. Linhas fundamentais da filosofia do direito ou Direito natural e ciência do estado em compêndio. Tradução de Paulo Menezes, Agemir Bavaresco, Alfredo Moraes, Danilo Vaz-Curado R. M. Costa, Greice Ane Barbieri e Paulo Roberto Konzen. 2a ed. São Leopoldo: UNISINOS, 2010. p. 197

\begin{tabular}{|c|c|c|c|c|c|}
\hline intuitio & $\begin{array}{c}\text { ISSN } \\
1983-4012\end{array}$ & Porto Alegre & Vol.10 $-\mathrm{N}^{\mathrm{o}} .1$ & $\begin{array}{l}\text { Julho } \\
2017\end{array}$ & p. 123-134 \\
\hline
\end{tabular}


O Conceito de Trabalho e o Trabalho do Conceito na Filosofia de Hegel: apontamentos introdutórios

O mesmo se pode dizer do trabalho, que é, de modo duplo, o espírito saindo de si e pondo-se no elemento da permanência (natureza), mas é também a natureza saindo de si e recebendo uma teleologia, portanto, é a natureza inscrita na ordem humana da liberdade. É pela mediação do trabalho, escrevera Hegel na dialética do senhor e do escravo, que a consciência chega a si mesma e se transforma no outro de si, realizando aquela suprassunção dialética que a faz tornar-se humana no reconhecimento. ${ }^{11}$

Esse espírito é o que também está na análise do trabalho, pois se começa por um momento em que a consciência está sendo subjugada, dominada, e mesmo com essa dominação ela consegue alçar-se a um novo patamar. É a ação do trabalho que lhe permite ir ascendendo à liberdade, ainda destacando os elementos da produção coletiva, na qual todos participam produzindo e gozando dos bens. Por fim, é nessas últimas passagens sobre a substituição do trabalho humano pelo mecânico o momento mais evidente dessa ideia de progresso.

\section{O trabalho do conceito}

Mas não podemos nos limitar a achar que a reflexão hegeliana sobre o trabalho está limitada ao mundo laborativo, ou seja, o trabalho também está no espírito. O espírito trabalha no seu processo de reconciliação consigo mesmo, não somente as consciências mundanas, mas nessa busca pelo saber absoluto, um saber que se sabe.

Analisemos a seguinte passagem:

Os pensamentos verdadeiros e a intelecção científica só se alcançam no trabalho do conceito. Só ele pode produzir a universalidade do saber, que não é a indeterminação e a miséria correntes do senso comum, mas um conhecimento cultivado e completo; não é a universalidade extraordinária dos dotes da razão que se corrompe pela preguiça e soberba do gênio; mas sim, é a verdade que se desenvolveu até sua forma genuína, e é capaz de ser a propriedade de toda a razão consciente-de-si ${ }^{12}$

Aponta-nos Hegel que há um trabalho para se alcançar o conceito, algo necessário para que se chegue à produção de um saber, que vá além do senso comum sobre as coisas. É este saber mais completo que exige o trabalho do conceito na sua mais alta acepção. Então, não há conhecimento sem esforço, sem sofrimento, pois se no ato de trabalhar para se produzir as coisas que são necessárias à satisfação das necessidades dos indivíduos temos de despender energia, temos de fazer esforço, não seria diferente com a

\footnotetext{
${ }^{11}$ SANTOS, J. H.. Trabalho e riqueza na Fenomenologia do Espírito de Hegel. São Paulo: Loyola, 1993. p. 120.

${ }^{12}$ HEGEL, G. W. F. Fenomenologia do espírito. Tradução de Paulo Meneses; com a colaboração de Karl-Heinz Efken e José Nogueira Machado. $7^{\mathrm{a}}$ ed. Petrópolis: Vozes; Bragança Paulista: Editora Universitária São Francisco, 2012. p. 69.
}

\begin{tabular}{|c|c|c|c|c|c|}
\hline intuitio & $\begin{array}{c}\text { ISSN } \\
1983-4012\end{array}$ & Porto Alegre & Vol.10 - No.1 & $\begin{array}{l}\text { Julho } \\
2017\end{array}$ & p. 123-134 \\
\hline
\end{tabular}


persecução que temos na busca pela plenitude da razão, já que é necessário muito trabalho para se alcançar o conceito.

Logo, não há conceito no mundo enquanto não houver, nesse mundo, tempo-queexiste-empiricamente. Ora, vimos que a existência-empírica do tempo no mundo é o desejo humano (isto é, o desejo que se dirige a um desejo como desejo). Logo, não há compreensão-conceptual sem desejo. Ora, o desejo se realiza pela ação negadora; e o desejo humano se realiza pela vitória do senhor sobre o escravo, e pelo trabalho deste último a serviço do senhor. É o trabalho do escravo que realiza o desejo do senhor ao satisfazê-lo. Logo, não há conceito sem trabalho; é do trabalho do escravo que nascem o entendimento (Verstand) e o pensamento (Denken), isto é, a compreensão conceptual do mundo. ${ }^{13}$

Assim temos que a filosofia hegeliana assume o trabalho também na sua própria consecução, ou seja, não se limita à restrição da análise do trabalho no mundo, de como as pessoas produzem as coisas, mas vai além, mostra que para se fazer ciência é necessário um trabalho sobre o conceito. Não temos um limite sobre a dialética do senhor e do escravo nessa análise, mas ele ainda destaca que o trabalho está presente na ação do espírito, pois para que ocorra o processo de reconciliação do espírito consigo mesmo se tem um trabalho.

Vejamos: "O movimento, que faz surgir a forma de seu saber de si, é o trabalho que o espírito executa como história efetiva" ${ }^{14}$. Então, temos que para Hegel também há um trabalho do espírito que vai executando a realização da história, ou seja, as figuras que temos na fenomenologia são o trabalho do espírito para reencontrar-se consigo mesmo, há um esforço do espírito para que chegue no saber absoluto, não é algo determinado, destinado. Pois, se o espírito não tivesse esse esforço não teria essa reconciliação do espírito consigo mesmo para chegar no saber absoluto.

\section{Considerações Finais}

Depreendemos daqui a ideia de dialética hegeliana, que se constitui numa sucessão de movimentos, ou seja, temos um momento inicial, e a sua posterior negação, desses dois momentos sai-se um terceiro momento, que supera ambos, mas conserva elementos dos mesmos. Assim temos o que se convencionou chamar de movimento triádico, em que se apresenta uma tese, a sua antítese e o resultado das duas: a síntese. A dialética hegeliana tem na sua gênese o elemento do constante processo de

${ }^{13}$ KOJÈVE, A. Introdução à leitura de Hegel. Tradução Estela dos Santos Abreu. Rio de Janeiro: Contraponto, 2014. p. 356.

${ }^{14}$ HEGEL, G. W. F. Fenomenologia do espírito. Tradução de Paulo Meneses com a colaboração de Karl-Heinz Efken e José Nogueira Machado. $7^{a}$ ed. Petrópolis: Vozes; Bragança Paulista: Editora Universitária São Francisco, 2012. p. 540.

\begin{tabular}{|c|c|l|l|l|l|}
\hline intuitio & $\begin{array}{c}\text { ISSN } \\
1983-4012\end{array}$ & Porto Alegre & Vol.10 $-\mathrm{N}^{\mathrm{o}} .1$ & $\begin{array}{l}\text { Julho } \\
2017\end{array}$ & p. 123-134 \\
\hline
\end{tabular}


O Conceito de Trabalho e o Trabalho do Conceito na Filosofia de Hegel: apontamentos introdutórios

movimentação, para tanto ele se utiliza de um termo alemão, o Aufhebung, que em língua portuguesa é vertido por suprassunção, que passa justamente essa ideia da conservação e superação do estado anterior.

Assim temos que a dialética do trabalho para a filosofia hegeliana tem como escopo justamente a ideia de que a história do trabalho vem se apresentando ao espírito numa sucessão de figuras que vão sendo superadas, mas conservadas até se atingir a relação da produção individual com a produção de todos, a riqueza em que todos participam e todos gozam. E da possibilidade de superação do trabalho humano pelo trabalho mecânico. E, dentro desse mesmo espírito temos que o trabalho está na base de ação do próprio espírito para ir forjando, pela sua ação, cada uma das figuras na busca da reconciliação consigo mesmo. Assim temos um espírito do trabalho e um trabalho do espírito.

\section{Referências}

HEGEL, G. W. F. Enciclopédia das ciências filosóficas em compêndio: 1830. Texto completo com os adendos orais, traduzido por Paulo Menezes com a colaboração de José Machado. $2^{a}$ ed. São Paulo: Loyola, 2011.

. Fenomenologia do espírito. Tradução de Paulo Meneses com a colaboração de Karl-Heinz Efken e José Nogueira Machado. $7^{\mathfrak{a}}$ ed. Petrópolis: Vozes; Bragança Paulista: Editora Universitária São Francisco, 2012.

. Linhas fundamentais da filosofia do direito ou Direito natural e ciência do estado em compêndio. Tradução de Paulo Menezes, Agemir Bavaresco, Alfredo Moraes, Danilo Vaz-Curado R. M. Costa, Greice Ane Barbieri e Paulo Roberto Konzen. $2^{\mathrm{a}}$ ed. São Leopoldo: UNISINOS, 2010.

HYPPOLITE, J. Gênese e estrutura da Fenomenologia do espírito de Hegel. Tradução de Sílvio Rosa Filho. $2^{\mathrm{a}}$ ed. São Paulo: Discurso Editorial, 2003.

KOJÈVE, A. Introdução à leitura de Hegel. Tradução Estela dos Santos Abreu. Rio de Janeiro: Contraponto, 2014.

SANTOS, J. H. Trabalho e riqueza na Fenomenologia do espírito de Hegel. (Coleção Filosofia - 30) São Paulo: Loyola, 1993.

Recebido em: 08/05/2016

Aprovado para a publicação em: 25/01/2017

\begin{tabular}{|c|c|l|l|l|l|}
\hline intuitio & $\begin{array}{c}\text { ISSN } \\
1983-4012\end{array}$ & Porto Alegre & Vol.10 $-\mathrm{N}^{\mathrm{o}} .1$ & $\begin{array}{l}\text { Julho } \\
2017\end{array}$ & p. 123-134 \\
\hline
\end{tabular}

